\title{
Zinc intake and status in Australian vegetarians
}

\author{
M. J. Ball* and M. L. Ackland \\ School of Biological and Chemical Sciences, Deakin University, Melbourne, Australia
}

(Received 11 August 1998 - Revised 17 June 1999 - Accepted 13 July 1999)

\begin{abstract}
Vegetarians have a lower incidence of many chronic diseases than omnivores. However, vegetarian diets could potentially result in lower intakes of some minerals, particularly $\mathrm{Zn}$. In a cross-sectional study, dietary $\mathrm{Zn}$ intake was measured using $12 \mathrm{~d}$ weighed records in ninetynine vegetarians (ten vegans) aged 18-50 years and forty-nine age- and sex-matched omnivores. In men, the mean daily $\mathrm{Zn}$ intake and $\mathrm{Zn}$ density values were similar in omnivores, ovolactovegetarians and vegans, but in women they were significantly lower in vegetarians (mean intake $6.8 \mathrm{mg} v .8 .4 \mathrm{mg}$ in omnivores) and few achieved the recommended intake. Significantly more vegetarian than omnivorous women had a daily $\mathrm{Zn}$ intake $<6 \mathrm{mg}(44 \% v .13 \%)$. Mean serum $\mathrm{Zn}$ concentrations were similar in female omnivores and vegetarians, despite the differences in intake. However, omnivorous men had a lower mean serum $\mathrm{Zn}$ concentration $(0 \cdot 85 \mu \mathrm{g} / \mathrm{ml} v$. $0.95 \mu \mathrm{g} / \mathrm{ml})$ and more subjects had levels below the reference range of $0.72-1.44 \mu \mathrm{g} / \mathrm{ml}$ than ovolactovegetarians $(P<0 \cdot 01)$. Overall more women than men had low $\mathrm{Zn}$ concentrations; and these women generally had intakes below $6 \mathrm{mg} / \mathrm{d}$. There was a significant correlation between serum $\mathrm{Zn}$ concentration and dietary $\mathrm{Zn}$ density in vegetarians, especially females $(P<0.001)$, but not in omnivores. Ovolactovegetarians did not have a significantly greater risk of low $\mathrm{Zn}$ status than omnivores.
\end{abstract}

\section{Zinc: Vegetarians}

Vegetarian diets have become increasingly popular in a number of countries in recent years for health, philosophical, ecological and religious reasons. In the 1995 National Nutrition Survey (McLennan \& Podger, 1995) self-reported prevalence of vegetarianism in Australian adults was $4.9 \%$ in females and $2.6 \%$ in males. The highest prevalence was in females aged 19-24 years (6.2\%). Vegetarians appear to have a lower morbidity and mortality from a number of chronic diseases, including cardiovascular disease and some cancers (Dwyer, 1988). These effects may be attributable to diet and to other lifestyle differences. However, there is concern over whether vegetarians, and particularly vegans, have an adequate intake of several minerals, particularly Fe, $\mathrm{Zn}$ and Ca (Kadrabova et al. 1995; Donovan \& Gibson, 1996).

$\mathrm{Zn}$ is an essential trace mineral that is a constituent of enzymes involved in most metabolic pathways, and is important for protein metabolism, cell growth and repair, and immune function. The long-term effects of mild deficiency are unclear, but it has been suggested that they include delayed wound healing, suboptimal immune functioning, increased plasma lipid peroxides and perhaps reduced taste and smell acuity seen in the elderly (Greger, 1989; Fortes et al. 1997). Serum Zn, hair Zn and salivary Zn have been used to assess status, although all have drawbacks (O’Dell, 1996). Zn status is subject to strong homeostatic regulation via the gut and liver, and individuals with poor $\mathrm{Zn}$ status absorb $\mathrm{Zn}$ more efficiently. The lack of sensitive indicators of $\mathrm{Zn}$ status and an absence of specific clinical features of mild deficiency, means that setting the recommended dietary intake (RDI) for $\mathrm{Zn}$ has proved difficult (O’Dell, 1996; Sandstead \& Smith, 1996). In Australia, the RDI has been set in the range of $6-12 \mathrm{mg} / \mathrm{d}$ (National Health and Medical Research Council, 1991), with many people using $12 \mathrm{mg}$.

In the Australian National Nutrition Survey (McLennan \& Podger, 1995) diet assessments using $24 \mathrm{~h}$ recall and a simple food-frequency questionnaire indicated that the mean intake of $\mathrm{Zn}$ from food and beverages was $16.8 \mathrm{mg}$ in adult Victorian males and $9.7 \mathrm{mg}$ in females, and was below the RDI in most female age groups. The composition of the diet affects the bioavailability of dietary $\mathrm{Zn}$ (Gibson, 1994). More $\mathrm{Zn}$ is generally available from animal sources than plant sources, and protein, insoluble fibre, phytate and 
some minerals, e.g. Fe, $\mathrm{Ca}$ and $\mathrm{P}$, can reduce $\mathrm{Zn}$ absorption. About two-thirds of the $\mathrm{Zn}$ consumed by most people in Australia is provided by animal products, particularly meat. Good plant sources of $\mathrm{Zn}$ are grains, nuts and legumes, and eggs, cheese and milk for ovolactovegetarians (Messina \& Burke, 1997).

A few previous studies have investigated $\mathrm{Zn}$ intake in vegetarians, and in vegetarians compared with omnivores, with variable findings (Freeland Graves et al. 1980; Levin et al. 1986; Alexander et al. 1994; Donovan \& Gibson, 1996). Reasonable-sized studies by Freeland Graves et al. (1980) and Levin et al. (1986) in both men and women revealed similar intakes, as assessed using $24 \mathrm{~h}$ diet recall and a food-frequency questionnaire. Most studies using diet records have measured dietary intake over just $1-4 \mathrm{~d}$ rather than the $12-14 \mathrm{~d}$ suggested as being required to obtain a more representative estimate of $\mathrm{Zn}$ intake (Marr \& Heady, 1986). Few studies have included a measure of $\mathrm{Zn}$ status such as serum $\mathrm{Zn}$ collected simultaneously with the dietary data.

The present study was conducted to measure $\mathrm{Zn}$ intake using $12 \mathrm{~d}$ weighed food records in Caucasian Australian vegetarian and vegan adults and in age- and sex-matched omnivores with similar lifestyles, and simultaneously to measure serum $\mathrm{Zn}$ concentrations.

\section{Experimental methods}

Fifty healthy non-pregnant female vegetarians aged 18-45 years and fifty male vegetarians aged 20-50 years were recruited in Victoria from advertisements on notice boards and in newspapers. For the purpose of the present study, a vegetarian was defined as someone who did not consume red meat, consumed fish or chicken less than once weekly and had been following this diet for at least 6 months. Vegetarian subjects were asked to recruit an age- and sexmatched 'friend' of similar BMI and smoking habit, who ate red meat at least three times per week, and half the subjects were able to do this. All subjects gave written informed consent for participation in the study, which was approved by the Ethics Committee of Deakin University.

All subjects completed a questionnaire requesting details about age, occupation, exercise and smoking habits, nutritional supplement use, the type of diet consumed, and the length of time they had followed the diet. Two volunteers who were trained athletes on special diets and supplements were excluded.

Subjects were asked to complete a $12 \mathrm{~d}$ weighed diet record, over three blocks of $4 \mathrm{~d}$ including three weekend days, and were given detailed instructions on how to complete this. A set of electronic scales (Bonso MiniScale) was provided for each subject. Where it was not possible to weigh food, subjects were told to describe the quantities consumed using either household measures or the photographs of representative portion sizes of common foods provided in the back of the diet record (Edington et al. 1988). The food and beverage intakes were entered into the dietary analysis program, 'Diet-3' (Xyris, Queensland, Australia), which is based on Australian food composition tables.

\section{Laboratory measurements}

Most subjects had a fasting venous blood sample taken at a time when they were not suffering from any infection during the fortnight after completion of the dietary record. The blood sample was collected in a $\mathrm{Zn}$-free tube, left standing at $4^{\circ}$ for $60 \mathrm{~min}$ and then centrifuged at $3000 \mathrm{rev} . / \mathrm{min}$ for $15 \mathrm{~min}$. The serum was separated and stored at $-20^{\circ}$. Serum $\mathrm{Zn}$ was analysed by flame atomic absorption spectroscopy (GBC 901, Melbourne, Australia) (Fell \& Lyon, 1994).

\section{Statistical analysis}

All statistical analyses were performed using SPSS version 8.0 (SPSS Australasia Pty Ltd, Sydney, Australia). The Mann-Whitney U-test was performed to determine differences between vegetarians and omnivores for nutrient intake and biochemical measurements, with ANOVA or the Kruskal-Wallis test being performed for greater than two groups depending on whether the Shapiro-Wilks test for normality indicated the data to be normally distributed or not. For dietary $\mathrm{Zn}$ intake the Shapiro-Wilks test on ovolactovegetarians gave a $P$ value of 0.05 ; analysis of results was then undertaken by both ANOVA and the Kruskal-Wallis test, and the results were the same. $\chi^{2}$ tests were performed to establish if the groups were significantly different with respect to numbers of subjects with values above or below cut-off points for nutrient and biochemical values. Spearman rank correlation and multiple regression analysis was performed to assess the relationships between dietary variables and serum $\mathrm{Zn}$ concentrations.

\section{Results \\ Subject characteristics}

Females. Forty-eight female ovolactovegetarians, two vegans and twenty-four omnivorous controls completed the study. The number of vegans was too small to warrant separate analysis so their data were included with those from the other vegetarian subjects. The vegetarians had been following the diet practice for a mean of $5 \cdot 2$ (range $1-17$ ) years. The mean age of vegetarian subjects was $25 \cdot 2$ years, compared with that of omnivores of 25.3 years. Vegetarians had a mean BMI of $22.5 \mathrm{~kg} / \mathrm{m}^{2}$ and omnivores $22.4 \mathrm{~kg} / \mathrm{m}^{2}$. These values were not significantly different. Most vegetarian and omnivorous subjects were students $(62.5 \%$ and $60.0 \%$ respectively), and the remainder were employed full-time except for one vegetarian subject who was unemployed. All subjects reported that they were in good health. There was no significant difference in the prevalence of regular cigarette smoking between the omnivores and vegetarians ( $8 \%$ and $16 \%$ respectively) or in reported level of physical activity or menstrual blood loss.

Males. Thirty-nine ovolactovegetarians, ten vegans and twenty-five omnivorous controls completed the study. The ovolactovegetarians and vegans had been following this dietary practice for a mean of 11 (range 0.5-44) years and 6 (range 1.5-14) years respectively. The omnivores did not differ significantly from either the ovolactovegetarians or 
Table 1. A comparison of daily dietary intakes in male and female omnivores and vegetarians from the present study (Mean values and standard deviations)

\begin{tabular}{|c|c|c|c|c|c|c|c|c|c|c|}
\hline \multirow[b]{3}{*}{ Dietary intake } & \multicolumn{6}{|c|}{ Males } & \multicolumn{4}{|c|}{ Females } \\
\hline & \multicolumn{2}{|c|}{ Omnivores $(n 25)$} & \multicolumn{2}{|c|}{$\begin{array}{c}\text { Ovolacto- } \\
\text { vegetarians }(n \text { 39) }\end{array}$} & \multicolumn{2}{|c|}{ Vegans $(n 10)$} & \multicolumn{2}{|c|}{ Omnivores (n 24) } & \multicolumn{2}{|c|}{ Vegetarians $(n 50)$} \\
\hline & Mean & SD & Mean & SD & Mean & SD & Mean & SD & Mean & SD \\
\hline Energy (MJ) & 11.0 & 1.9 & $10 \cdot 5$ & $2 \cdot 4$ & 11.6 & $2 \cdot 7$ & 6.9 & 1.4 & 6.9 & 1.9 \\
\hline Protein (g) & 108 & 17 & $80^{* *}$ & 16 & $81^{* *}$ & 24 & 67 & 16 & $54^{* *}$ & 15 \\
\hline Carbohydrate (g) & 291 & 77 & 357 & 92 & $414^{*}$ & 97 & 183 & 42 & 211 & 60 \\
\hline Fat $(\mathrm{g})$ & 98 & 32 & 82 & 28 & 88 & 38 & 65 & 17 & 60 & 22 \\
\hline Fibre $(\mathrm{g})$ & $26 \cdot 3$ & $7 \cdot 7$ & $49 \cdot 8^{* * *}$ & $15 \cdot 9$ & $63 \cdot 8^{* * *}$ & 14.6 & $17 \cdot 3$ & 4.9 & $24 \cdot 4^{\star \star \star}$ & 8.5 \\
\hline Iron (mg) & $15 \cdot 8$ & 4.5 & $20 \cdot 4$ & $7 \cdot 7$ & $22 \cdot 9$ & $6 \cdot 2$ & 9.9 & $2 \cdot 9$ & $10 \cdot 7$ & $4 \cdot 4$ \\
\hline
\end{tabular}

Mean values were significantly different from those for omnivores: ${ }^{*} P<0.05,{ }^{* *} P<0.01$, ${ }^{* * *} P<0.001$ (Mann Whitney $U$ test).

vegans with respect to age, smoking habit, BMI, waist : hip ratio or blood pressure.

\section{Dietary intake and zinc measurement}

Total energy intakes were similar for males and for females in the different diet groups, but vegetarians derived a significantly lower proportion of their energy from protein compared with omnivores. This was compensated for by a higher proportion of energy being derived from carbohydrate in men (Table 1).

The mean $\mathrm{Zn}$ intakes in the different dietary groups are shown in Table 2. In men, the Zn intake and Zn density (mg/ MJ energy) were not significantly different on the three types of diet, with mean intake at about the upper end of the RDI. Of male omnivores $36 \%$ had a dietary $\mathrm{Zn}$ intake below $12 \mathrm{mg} / \mathrm{d}$ as did $64 \%$ male ovolactovegetarians and $70 \%$ vegans (Fig. 1(a)). Two ovolactovegetarians had intakes of less than $6 \mathrm{mg} / \mathrm{d}$.

In both the omnivorous group and the vegetarian-vegan group, the females had significantly lower Zn intakes than the males $(P<0 \cdot 001)$. In women, the mean $\mathrm{Zn}$ intake of vegetarians $(6.8 \mathrm{mg} / \mathrm{d})$ was significantly lower than that of omnivores $(8.4 \mathrm{mg} / \mathrm{d} ; P<0.05)$, as was the $\mathrm{Zn}$ density (mg/MJ energy), $(P<0 \cdot 001)$. Only one omnivore and one vegetarian had a $\mathrm{Zn}$ intake above $12 \mathrm{mg} / \mathrm{d}$. The number of vegetarians with an intake of less than $6 \mathrm{mg} / \mathrm{d}(22 / 50)$ was significantly greater than the number of omnivores $(3 / 23)$. If data from females with a reported energy intake less than 1.2 times the calculated BMR were excluded, $\mathrm{Zn}$ intake in omnivores (8.9 (SD 1.8) mg) was still significantly higher than in vegetarians $(7.9$ (SD 2.4) $\mathrm{mg}$ ) and serum $\mathrm{Zn}$ levels in the two groups were not significantly different.

In ovolactovegetarians the predominant food sources of $\mathrm{Zn}$ were fruits, cheese, vegetables and cereals, whereas omnivores obtained much of their $\mathrm{Zn}$ from animal foods, i.e. meats and dairy products. Only three subjects (one omnivore) regularly took supplements containing $\mathrm{Zn}$ and exclusion of their data did not significantly influence the study results.

Nutrient intakes in the dietary groups are shown in Tables 1 and 2 . There was a significant positive correlation between dietary $\mathrm{Zn}$ and $\mathrm{Fe}$ intakes ( $r 0.68$ for vegetarians, and 0.83 for omnivores, $P<0.001)$ and also between dietary $\mathrm{Zn}$ and dietary fibre $(r 0.57, P<0.001)$.

The serum $\mathrm{Zn}$ concentrations are shown in Table 3. In men the serum $\mathrm{Zn}$ concentration was significantly higher in the ovolactovegetarians than in both the omnivores and vegans $(P<0 \cdot 01)$. No male ovolactovegetarians had serum concentrations below the lower end of the reference range of $0.72 \mu \mathrm{g} / \mathrm{ml}$, which has been proposed as indicating low status (Tietz, 1987), but three of the twenty-one omnivores, and one of the eight vegans did: these had intakes of $10,12.4$ and $14.1 \mathrm{mg}$, and $7.4 \mathrm{mg}$ respectively. The vegan took Fe and multivitamin supplements.

Serum $\mathrm{Zn}$ concentrations were not significantly different

Table 2. Dietary zinc intakes and zinc density of the diets of male and female omnivores and vegetarians in the present study (Median and mean values, standard deviations, ranges and $95 \%$ confidence intervals)

\begin{tabular}{|c|c|c|c|c|c|c|c|c|}
\hline & \multicolumn{6}{|c|}{ Dietary zinc intake (mg/d) } & \multicolumn{2}{|c|}{$\begin{array}{l}\text { Zinc density } \\
(\mathrm{mg} / \mathrm{MJ})\end{array}$} \\
\hline & $n$ & Median & Mean & SD & Range & $95 \% \mathrm{Cl}$ & Mean & SD \\
\hline \multicolumn{9}{|l|}{ Males } \\
\hline Omnivores & 25 & $12 \cdot 3$ & $12 \cdot 7$ & 2.4 & $9.5-16.9$ & $11 \cdot 7,13 \cdot 7$ & 1.17 & 0.19 \\
\hline Ovolactovegetarians & 39 & $11 \cdot 0$ & $11 \cdot 1$ & $3 \cdot 8$ & $5 \cdot 8-26 \cdot 1$ & $9 \cdot 8,12 \cdot 4$ & $1 \cdot 13$ & 0.31 \\
\hline Vegans & 10 & $11 \cdot 0$ & 11.9 & $3 \cdot 8$ & $7 \cdot 4-18 \cdot 1$ & $9 \cdot 2,14.5$ & $1 \cdot 10$ & 0.21 \\
\hline \multicolumn{9}{|l|}{ Females } \\
\hline Omnivores & 24 & 8.0 & 8.4 & $2 \cdot 1$ & $4 \cdot 6-13 \cdot 2$ & $7 \cdot 5,9 \cdot 2$ & 1.21 & 0.18 \\
\hline Vegetarians & 50 & $5 \cdot 8$ & $6 \cdot 8^{\star *}$ & $2 \cdot 4$ & $3 \cdot 1-17 \cdot 2$ & $6 \cdot 1,7 \cdot 5$ & $1.00^{\star \star}$ & 0.28 \\
\hline
\end{tabular}

Mean value was significantly different from that for female omnivores: ** $P<0.01$. 

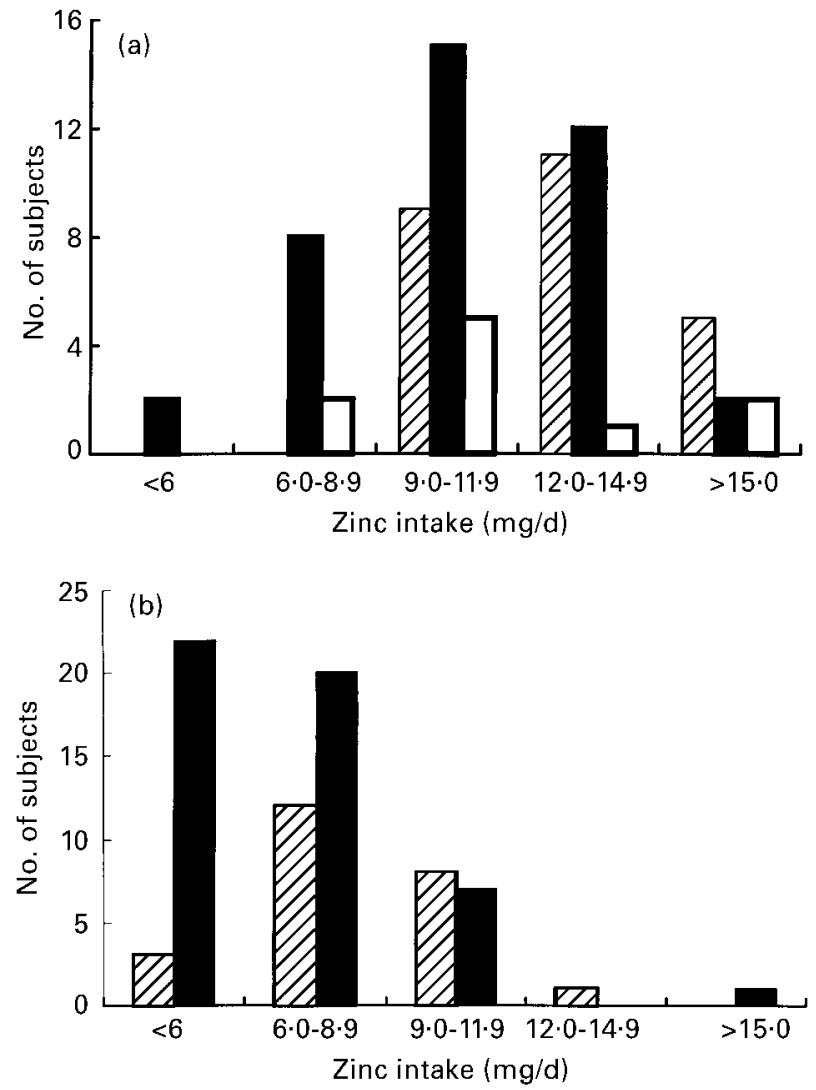

Fig. 1. Frequency distributions of dietary zinc intake in (a) male and (b) female omnivores (四), ovolactovegetarians ( $\square$ ) and vegans ( $\square$ ) in the present study.

in the female vegetarians and omnivores. Three of the twenty-one omnivores and nine of the thirty-nine vegetarians had concentrations below the reference range (their intakes being $4.8,5.9$ and $7.5 \mathrm{mg}$ in the omnivores and 7.5 , $8 \cdot 6,5 \cdot 7,6 \cdot 5,5 \cdot 7,5 \cdot 7,5 \cdot 1,5 \cdot 1$ and $3 \cdot 1 \mathrm{mg}$ in the vegetarians); thus two and six women respectively had $\mathrm{Zn}$ intakes below $6 \mathrm{mg} / \mathrm{d}$.

There was no significant correlation between serum $\mathrm{Zn}$ concentration and $\mathrm{Zn}$ intake/MJ energy (log values, as not normally distributed) in omnivorous males or females, but the correlation was significant in vegetarians $(r 0.48, P<$ $0.002)$, particularly female vegetarians. The pattern of the relationship in female vegetarians is shown in Fig. 2. At lower $\mathrm{Zn}$ densities there was no relationship, but at higher values there was a strong positive relationship, with a $\mathrm{CV}$ of 0.65 for values above $0.9 \mathrm{mg} / \mathrm{MJ}$. There was no significant effect on serum $\mathrm{Zn}$ concentrations of fibre or protein intake.

\section{Discussion}

Comprehensive weighed dietary records taken over a period of $12 \mathrm{~d}$ have enabled us to obtain data on $\mathrm{Zn}$ intake and consumption of other dietary components including fibre, $\mathrm{Fe}$ and total energy, and the simultaneous dietary $\mathrm{Zn}$ data and serum $\mathrm{Zn}$ measurements add to the available data. Energy intakes were low in some subjects but participants were generally lean and trained athletes had been excluded. Although completing diet records may affect consumption or lead to underreporting this should not be different in omnivores and vegetarians.

The $\mathrm{Zn}$ intakes were significantly higher in males than females, regardless of the diet. Similar results have been found in other studies comparing $\mathrm{Zn}$ intakes of male and female omnivores and vegetarians (Freeland Graves et al. 1980; Faber et al. 1986; Levin et al. 1986). In studies of females only, $\mathrm{Zn}$ intakes were generally lower than those found in men in similar populations (Faber et al. 1986; Janelle \& Barr, 1995; Donovan \& Gibson, 1996). In our present study the lower $\mathrm{Zn}$ intakes in females were largely related to lower energy intakes, and this is expected to be a factor in other studies, although most do not provide adjusted data and statistical analysis.

The finding of similar dietary $\mathrm{Zn}$ intakes in male ovolactovegetarians and omnivores was also obtained in the study by Levin et al. (1986) in Israel, but a smaller South African study using $7 \mathrm{~d}$ dietary records reported lower intakes in male vegetarians (Faber et al. 1986). Serum Zn levels were similar in the former study and were not measured in the latter study.

Our finding of significantly lower $\mathrm{Zn}$ intakes in female vegetarians than female omnivores has also been observed in other studies (Freeland Graves et al. 1980; Janelle \& Barr, 1995), although in some the differences were not statistically significant (Faber et al. 1986; Levin et al. 1986; Donovan \& Gibson, 1996) and the different dietary methodologies make comparison of actual intakes inappropriate. No significant difference in $\mathrm{Zn}$ intake was noted in a mixed

Table 3. Serum zinc concentrations in relation to zinc intakes in male and female omnivores and vegetarians in the present study

\begin{tabular}{|c|c|c|c|c|c|c|c|c|}
\hline & \multirow[b]{2}{*}{$n$} & \multicolumn{2}{|c|}{$\begin{array}{l}\text { Zinc intake } \\
(\mathrm{mg} / \mathrm{d})\end{array}$} & \multicolumn{5}{|c|}{ Serum zinc $(\mu \mathrm{g} / \mathrm{ml})$} \\
\hline & & Mean & SD & Mean & SD & Median & Range & $95 \% \mathrm{Cl}$ \\
\hline \multicolumn{9}{|l|}{ Males } \\
\hline Omnivores & 21 & $12 \cdot 8$ & 2.5 & 0.85 & 0.14 & 0.81 & $0.66-1.15$ & $0.78,0.91$ \\
\hline Ovolactovegetarians & 35 & 11.4 & 3.9 & $0.96^{* *}$ & 0.13 & 0.95 & $0.72-1.28$ & $0.92,1.01$ \\
\hline Vegans & 8 & $10 \cdot 9$ & 4.0 & 0.84 & $0 \cdot 15$ & 0.86 & $0.55-1.02$ & $0.72,0.97$ \\
\hline \multicolumn{9}{|l|}{ Females } \\
\hline Omnivores & 21 & $8 \cdot 3 \dagger$ & $2 \cdot 1$ & 0.91 & 0.15 & 0.92 & $0.67-1.22$ & $0.84,0.98$ \\
\hline Vegetarians & 39 & $6 \cdot 8$ & $2 \cdot 6$ & 0.87 & 0.18 & 0.85 & $0.63-1.31$ & $0.81,0.93$ \\
\hline
\end{tabular}

Mean value was significantly different from those for male omnivores and vegans: ${ }^{* *} P<0.01$.

Mean value was significantly different from that for female vegetarians: $\uparrow P<0.02$. 


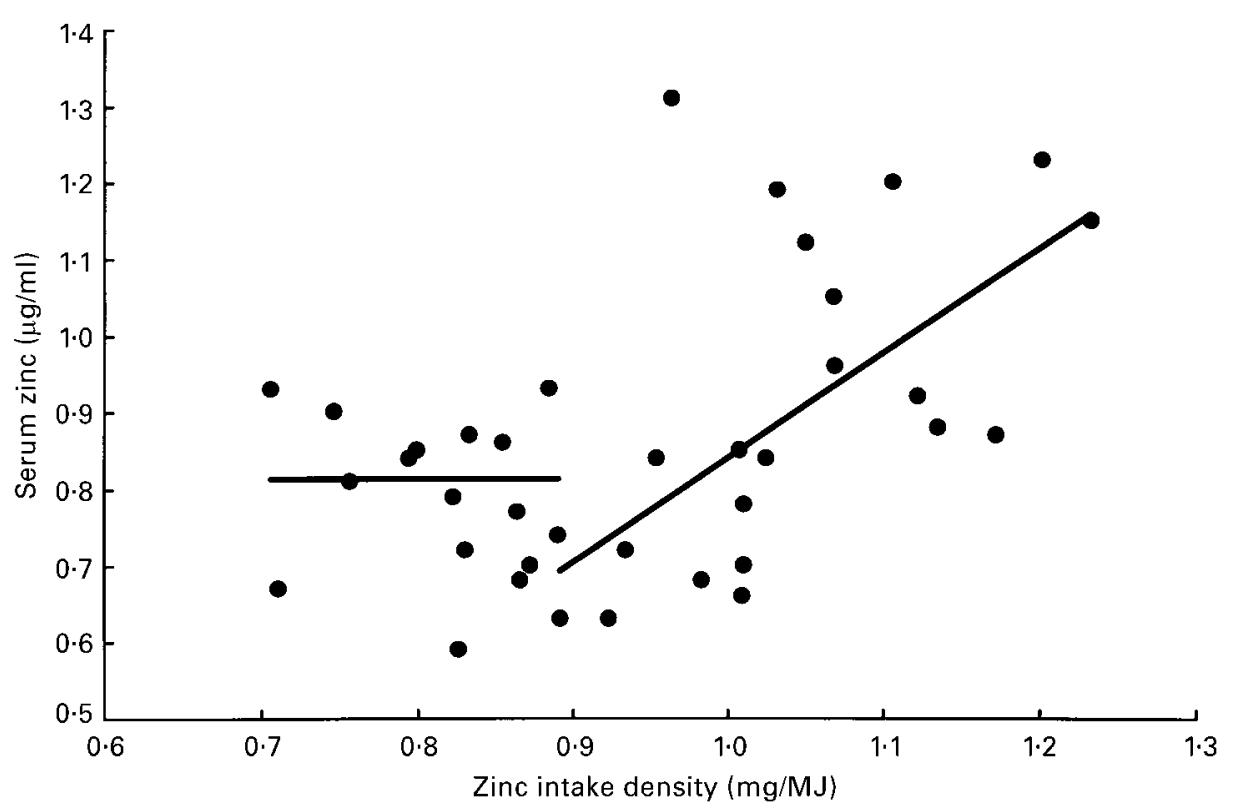

Fig. 2. Relationship between zinc intake density (mg/MJ) and serum zinc concentration in female vegetarians in the present study. Regression lines are shown for zinc intake densities below and above $0.9 \mathrm{mg} / \mathrm{MJ}$.

group of New Zealand males and females, using $12 \mathrm{~d}$ weighed records, although the small number of vegans had the lowest mean intake (Alexander et al. 1994).

Some low intakes may be due to dietary under-reporting. Several women had low energy intakes, although the mean energy intake expressed as a multiple of the calculated BMR (Schofield et al. 1985; Goldberg et al. 1991) was the same in omnivores and vegetarians, suggesting similar influences in both groups. Several women reported that they were 'dieting', despite being of normal BMI, but if this was a common feature of their life, they were not excluded. Separate analysis, removing data from women with recorded energy consumption of less than $1.2 \times$ calculated BMR, resulted in an increase in mean $\mathrm{Zn}$ intake in both groups, but the intake in the vegetarians was still significantly lower $(P<0.05)$.

In our present study, mean serum Zn concentrations for male and female subjects on all diets were within the laboratory normal 'reference' range for the method ( $0 \cdot 72$ $1.44 \mu \mathrm{g} / \mathrm{ml}$ ). Physiological stress affects plasma $\mathrm{Zn}$ concentration, but in this study (and most with which it is compared) subjects were healthy and blood sampling was not undertaken if they had an infection in order to reduce any influences. Blood specimens were also taken while fasting (between 08.00 and 10.00 hours) to minimize any effect of diurnal variation.

Despite the fact that most female vegetarians had low $\mathrm{Zn}$ intakes, serum levels were not significantly lower than in the omnivores. This may reflect compensation with increased absorption of $\mathrm{Zn}$ in those with low intakes or status, and/or an adaptation to a long-term vegetarian diet with changes in availability or metabolism. The latter factor might also explain the surprising finding that ovolactovegetarian men had a higher serum $\mathrm{Zn}$ concentration than omnivores despite similar intakes, and that more omnivorous men had values below the reference range. Interestingly, these men had intakes $\geqslant 10 \mathrm{mg}$, whereas most of the women omnivores with low serum levels had intakes $<6 \mathrm{mg}$.

Most of our subjects obtained considerable amounts of their $\mathrm{Zn}$ from cheese and eggs, which may be more bioavailable than that from breads, cereals and vegetables. The inhibiting effect of phytate on $\mathrm{Zn}$ absorption has been quantified by the ratio phytate:Zn (Gibson, 1994), and foods with high ratios include sorghum, groundnuts, cowpeas, unleavened bread and unprocessed soyabean protein concentrates. These foods may constitute a high proportion of vegetarian diets in some countries and were high in the diet of the Trappist monks who had low serum Zn levels (Harland \& Peterson, 1978), but are not common in Australian diets. The vegetarian diets were higher in fibre, but investigators differ in their opinion of whether insoluble cereal and vegetable fibres inhibit $\mathrm{Zn}$ bioavailability. In our study there was no relationship between fibre intake and serum $\mathrm{Zn}$ concentration, and no relationship was found in Retzlaff's study (Retzlaff et al. 1995) in over 300 hypercholesterolaemic men on a low-fat, increased fibre diet. Intakes of $\mathrm{Ca}$ and haem $\mathrm{Fe}$, which can also inhibit $\mathrm{Zn}$ absorption, were higher in omnivores, although intake from food would probably be insufficient to have a significant effect in the absence of supplement ingestion (Wood \& Zheng, 1995).

The pattern of the relationship between $\mathrm{Zn}$ density and serum $\mathrm{Zn}$ concentration in female vegetarians may indicate that at lower intakes absorbed $\mathrm{Zn}$ is rapidly taken into tissues and does not increase the plasma $\mathrm{Zn}$, but at higher intakes it is available to influence the plasma levels. The reason for the strong correlation only in vegetarian women is unclear, although the wider range of values may make this more apparent and perhaps there are differences in binding and metabolism related to the different amino acid profiles 
in vegetarians and omnivores. A logarithmic relationship between the daily intake of $\mathrm{Zn}$ and the quantity absorbed has been described (World Health Organization Committee, 1996), but our understanding of the mechanisms of $\mathrm{Zn}$ homeostasis, metabolism and conservation remains incomplete.

Freeland Graves et al. (1980) compared seventy-nine vegetarians (forty-three men) with forty-one non-vegetarians (forty women), but there was no matching by age, BMI etc. and the controls were University students and Faculty, who differed in education status to the subjects. Mean dietary $\mathrm{Zn}$ intake $(24 \mathrm{~h}$ recall) was $8.5 \mathrm{mg}$ in vegetarians, with most subjects having intakes below the recommended dietary allowance (National Research Council, 1989) compared with $10.1 \mathrm{mg}$ in omnivores and only $1.5 \mathrm{mg}$ in the four vegans. Comparisons in men were not possible as only one male omnivore was studied. Serum $\mathrm{Zn}$ was not documented separately for men and women, reducing the opportunity for comparison with our study. The $\mathrm{Zn}$ content of salivary sediment and hair was, however, noted to be significantly lower in vegetarians, raising the authors' concerns that some women vegetarians had less than satisfactory $\mathrm{Zn}$ status.

Anderson et al. (1981) studied fifty-six Seventh Day Adventist Canadian women (mean age 53 years) on longterm vegetarian diets. Dietary records $(3 \mathrm{~d})$ revealed a mean

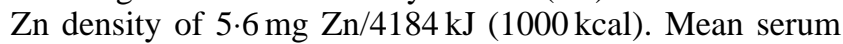
$\mathrm{Zn}$ concentration was 0.99 (SD 0.24$) \mu \mathrm{g} / \mathrm{ml}$. In these women, who were generally older than those in our present study, both serum levels and $\mathrm{Zn}$ intakes were higher with a greater range of values, and the mean $\mathrm{Zn}$ density of the diet (mg/MJ) was about $20 \%$ greater. No vegetarians had hair $\mathrm{Zn}$ levels below $70 \mathrm{mg} / \mathrm{kg}$, suggestive of suboptimal $\mathrm{Zn}$ status. In older Seventh Day Adventist women (mean age over 70 years) Nieman et al. (1989) found similar mean levels in the twenty-three vegetarians and fourteen nonvegetarians of $6.28 \mathrm{mg}$ and $6.29 \mathrm{mg}$ respectively; energy intake was slightly lower than in the present study, probably because participants were older, but serum $\mathrm{Zn}$ was not measured.

In Swedish subjects (Srikumar et al. 1992a,b) who changed from a mixed diet to a lacto-vegetarian diet, mean $\mathrm{Zn}$ intake remained constant at $12 \mathrm{mg} / 10 \mathrm{MJ}$, but energy intake fell by about $10 \%$ over 1 year and plasma $\mathrm{Zn}$ was $13 \%$ lower at 3 months but was then stable.

A small study by King et al. (1981) revealed a mean plasma $\mathrm{Zn}$ level about $20 \%$ lower in pregnant vegetarians than in five non-pregnant vegetarian women, even though the pregnant women consumed more $\mathrm{Zn}$. This is difficult to interpret as proteins change in pregnancy, but as $\mathrm{Zn}$ requirement is increased during pregnancy, pregnant vegetarians might be more likely to develop poor Zn status.

Sandstead \& Smith (1996) have questioned whether the RDI for Zn might be set too high. Most surveys of subjects with mean intakes below the RDI have shown few with low serum or hair $\mathrm{Zn}$ concentrations. A poor correlation between low intake and serum $\mathrm{Zn}$ level, as seen in the present study, and a lack of information on what constitutes low status with impaired physiological functioning, compound the problem. The situation is also complicated by other dietary factors, and varying patterns of food intake over time, and lifestyle factors may also be significant in determining $\mathrm{Zn}$ requirements (Sandstead \& Smith, 1996). The World Health
Organization Committee (1996) suggest the estimation of 'basal' and 'normative' requirements, where basal requirement is the minimal amount needed to replace obligatory $\mathrm{Zn}$ loss in persons 'adapted' to low intakes.

There are several studies now indicating that vegetarian diets are more likely to be low in fat and high in fibre and to meet the dietary guidelines of many countries, including Australia, the USA and the UK. It would appear that $\mathrm{Zn}$ deficiency is not a specific problem for healthy ovolactovegetarians in Victoria, although it might be in vegans or vegetarians who have additional dietary restrictions, or during pregnancy. Mineral deficiency can, however, occur in both vegetarians and omnivores and it is important that people in high-risk groups, particularly adolescents and premenopausal women and those with low energy intakes, are advised to eat a nutritious balance of mineral-rich foods and that there is the opportunity to assess $\mathrm{Zn}$ status in those whose diets and/or lifestyle give cause for concern.

\section{Acknowledgements}

Melinda Bartlett and Alisa Wilson expertly collected the dietary data for some of the subjects. Dr Iain Robertson provided expert statistical advice.

\section{References}

Alexander D, Ball MJ \& Mann J (1994) Nutrient intake and haematological status of vegetarians and age-sex matched omnivores. European Journal of Clinical Nutrition 48, 538-546.

Anderson BM, Gibson RS \& Sabry JH (1981) The iron and Zn status of long-term vegetarian women. American Journal of Clinical Nutrition 34, 1042-1048.

Donovan UM \& Gibson RS (1996) Dietary intakes of adolescent females consuming vegetarian, semi-vegetarian, and omnivorous diets. Journal of Adolescent Health 18, 292-300.

Dwyer JT (1988) Health aspects of vegetarian diets. American Journal of Clinical Nutrition 48, 712-738.

Edington J, Thorogood M, Geekie M, Ball M \& Mann J (1988) Assessment of nutritional intake using dietary records with estimated weights. Journal of Human Nutrition and Dietetics 2, 407-441.

Faber M, Gouws E, Benade AJ \& Labadarios D (1986) Anthropometric measurements, dietary intake and biochemical data of South African lacto-ovovegetarians. South African Medical Journal 69, 733-738.

Fell G \& Lyon T (1994) Zinc. In Trace Element Analysis in Biological Specimens. Techniques and Instrumentation in Analytical Chemistry, vol. 15, p. 553 [R Herber and M Stoeppler, editors]. Amsterdam: Elsevier.

Fortes C, Agabiti N, Fano V, Pacifici R, Forastiere F, Virgili F, Zuccaro P, Perruci CA \& Ebrahim S (1997) Zinc supplementation and plasma lipid peroxides in an elderly population. European Journal of Clinical Nutrition 51, 97-101.

Freeland Graves JH, Bodzy PW \& Eppright MA (1980) Zinc status of vegetarians. Journal of the American Dietetic Association 77, 655-661.

Gibson RS (1994) Content and bioavailability of trace elements in vegetarian diets. American Journal of Clinical Nutrition 59, $1223 \mathrm{~s}-1232 \mathrm{~s}$.

Greger JL (1989) Potential for trace mineral deficiencies and toxicities in the elderly. In Mineral Homeostasis in the Elderly. Current Topics in Nutrition and Disease, vol. 21, pp. 171-200 [CW Bales, editor]. New York, NY: Alan R. Liss. 
Goldberg G, Black A, Jebb S, Cole T, Murgatroyd P, Coward W \& Prentice AM (1991) Critical evaluation of energy intake data using fundamental principles of energy physiology. European Journal of Clinical Nutrition 45, 569-581.

Harland BF \& Peterson M (1978) Nutritional status of lacto-ovo vegetarian Trappist monks. Journal of the American Dietetic Association 72, 259-264.

Janelle KC \& Barr SI (1995) Nutrient intakes and eating behavior scores of vegetarian and nonvegetarian women. Journal of the American Dietetic Association 95, 180-186.

Kadrabova J, Madaric A, Kovacikova Z \& Ginter E (1995) Selenium status, plasma zinc, copper, and magnesium in vegetarians. Biological Trace Element Research 50, 13-24.

King JC, Stein T \& Doyle M (1981) Effect of vegetarianism on the zinc status of pregnant women. American Journal of Clinical Nutrition 34, 1049-1055.

Levin N, Rattan J \& Gilat T (1986) Mineral intake and blood levels in vegetarians. Israeli Journal of Medical Sciences 22 , $105-108$.

McLennan W \& Podger A (1995) National Nutrition Survey Selected Highlights in Australia. Canberra: Australian Bureau of Statistics.

Marr JW \& Heady JA (1986) Within- and between-person variation in dietary surveys: number of days needed to classify individuals. Human Nutrition: Applied Nutrition 40, 347-364.

Messina VK \& Burke KI (1997) Position of the American Dietetic Association: vegetarian diets. Journal of the American Dietetic Association 97, 1317-1321.

National Health and Medical Research Council (1991) NHMRC Recommended Dietary Intakes for use in Australia. Canberra: Australian Government Publishing Service.

National Research Council (1989) Recommended Dietary Allowances, 10th ed. Washington, DC: National Academy Press.

Nieman DC, Underwood BC, Sherman KM, Arabatzis K,
Barbosa JC, Johnson M \& Shultz TD (1989) Dietary status of Seventh-Day Adventist vegetarian and non-vegetarian elderly women. Journal of the American Dietetic Association 89, 17631769.

O'Dell BL (1996) Endpoints for determining mineral element requirements; an introduction. Journal of Nutrition 126, 2342s-2344s.

Retzlaff BM, Walden CE, McNeney WB, Dowdy AA \& Knopp RH (1995) Zinc intake and plasma zinc level are maintained in men consuming cholesterol-lowering diets. Journal of the American Dietetic Association 95, 1274-1279.

Sandstead HH \& Smith JC Jr (1996) Deliberations and evaluations of approaches, endpoints and paradigms for determining zinc dietary recommendations. Journal of Nutrition 126, 2410s2418s.

Schofield WN (1985) Predicting basal metabolic rate, new standards and review of previous work. Human Nutrition: Clinical Nutrition 39C, Suppl. 1, 5-41.

Srikumar TS, Johansson GK, Ockerman PA, Gustafsson JA \& Akesson B (1992a) Trace element status in healthy subjects switching from a mixed to a lactovegetarian diet for $12 \mathrm{mo}$. American Journal of Clinical Nutrition 55, 885-890.

Srikumar TS, Kallgard B, Ockerman PA \& Akesson B (1992b) The effects of a 2-year switch from a mixed to a lactovegetarian diet on trace element status in hypertensive subjects. European Journal of Clinical Nutrition 46, 661-669.

Tietz N (1987) Fundamentals of Clinical Chemistry. Philadelphia, PA: W.B. Saunders Co.

Wood R \& Zheng J (1995) Calcium supplementation reduces intestinal zinc absorption and balance in humans. FASEB Journal 9, A1640.

World Health Organization Committee (1996) Zinc. In Trace Elements in Human Nutrition and Health, pp. 72-104. Geneva: WHO. 